\title{
Splendour and Miseries of Architectural Construction Drawings
}

\section{Marco Frascari}

The painting will move the soul of the beholder when the people painted there each clearly shows the movement of his own soul ... we weep with the weeping, laugh with the laughing, and grieve with the grieving. These movements of the soul are known from the movements of the body. (Leon Battista Alberti, On Painting)

The architectural profession has created an almost unbridgeable chasm between subjective design drawings and objective production documents. For design drawings, there are no established conventions, because they would interfere with the creativity of architects, but for construction drawings, most of which are objective documents, the logical conclusion is that they should have been easily codified. However, architects have had an incredibly hard time agreeing on construction notations, a predicament which is probably as old as the Biblical turris confusionis and Nimrod's rave, "Rafel mai amech sabi almi," meaningless to anyone but himself. As a consequence of this peculiar condition, many architects, and most architectural firms, have their own systems.

After a confusing beginning, musicians eventually accepted a common system of notation, but architects have not been capable of doing so, despite many attempts at unification and standardisation by nations and architectural associations. The reason is simple: neither the normative nor the arbitrary can figure out the emotional process of creating "sound edifices and structures"; the lines of construction drawings evoke strong feelings. However, the birth and growth of CAD and BIM are achieving a graphic unification of construction drawings. As a result, architecture is slowly becoming aphonic and impassive. Nevertheless, this depressing result demonstrates that construction drawings are a powerful apparatus that can, in addition to informing the facture of buildings, encapsulate, orient, ascertain, interpret, model, control or secure the gestures, behaviours, opinions or discourses of the people who are involved in the making of architecture.

In their present unemotional form, construction drawings have been a quite recent attainment. They are an authority apparatus devised by North American architects to wrest control of the architectural market away from the builders at the beginning of the nineteenth century (see Ortenberg 2005). Taking advantage of the Greek Revival, a style fashionable when this market struggle took place, the graphic models selected for construction drawings were the archaeological drawings of Classical monuments such as those produced by Thomas Major for his 1768 book of prints, The Ruins of Paestum. By the mid-nineteenth century, American offices had come to resemble today's architectural firms and had generated the orthodox understanding that sees construction drawings as visual (graphic) information, prepared by an architectural team for use by construction

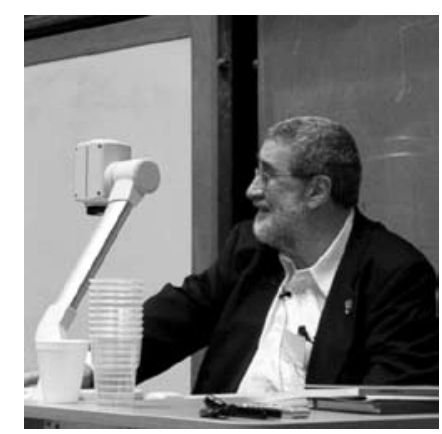


contractors and subcontractors. The main purpose of construction drawings is to define the size, shape, location and construction of a building and its parts. Even if the original intention of the construction drawings, modelled after aseptic archaeological drawings, was to demonstrate the architects' pre-eminence in conceiving architecture and its detailing, the present construction drawings, drafted by many hands, are considered merely protective legal documents that translate a design construct into prescriptions for a construction.

In these sets of construction drawings, a visual rhetoric of mono-directional translations is the unacknowledged mode of production. Both academic and professional architects regard this arrangement of the architect's work as necessary and financially useful for billing clients, but a prosaic part of the making of architecture. For them, it is a superintendence problem to prepare documents that instruct the builder how to make buildings looking like the presentation drawings produced by the designer. A flawless management of production is the accepted solution by many firms and architects to the problem of construction drawings, even if it produces time-consuming and uninspiring documents with no connection to a maturation of real and proper architectural artefacts.

The facture of construction drawings is not as obvious as the marketing for digital architectural instruments would have architects, builders and clients believe. This facture does not presume that traces, lines and scores in the drawings are worldly or unworldly, existing or non-existing, physical or mental, subjective or objective. The only thing that the facture assumes is that that which is marked, inked, pencilled, brushed, chalked and printed comes into the being of architectural artefact. Construction drawings are, in other words, wholly based on a sapience of materialisation, where material lines become powerful carriers of fluid and invisible lines, thoughts to be transubstantiated in brick and mortar.

To propose a change of the present trend of construction drawings is crucial to recall a traditional form of non-trivial construction drawings that accept them as an essential part of the process not separated from design drawing. To explain this possibility a novel neurological paradigm can be used. By rising from medieval tracing floors to paper, non-trivial construction drawings have evolved in a specific manifestation of non-verbal thinking, realised by either involuntary or purposeful comparison of the impressions of different sensorial modalities, based on structural or semantic and, most of all, emotional similarity. These non-trivial construction drawings are not merely factual information providing the likeness of the thing represented, but rather a programme of intentions that is to be revealed through the process of making. Thus conceived, construction drawings allow a dialogue between the imagination of builders and the imagination of architects; they are drawings that grow and develop the making of architecture rather than relegating it to predetermined and inflexible impositions. The process is not just a matter of imposing likenesses on the builder by merely showing a still image, but rather the aim is to influence the results by producing images of becoming. Construction drawings are, in other words, wholly based on a sapience of materialisation, where material lines become the carriers of fluid and invisible lines, thoughts.

The ineffable nature of a non-trivial construction drawing is based on the somasensory brain. Architects express their hopes and desires, their vision of society and humanity not only in their design drawings but also through construction drawings by producing architectural artefacts that first respond to the builders' 


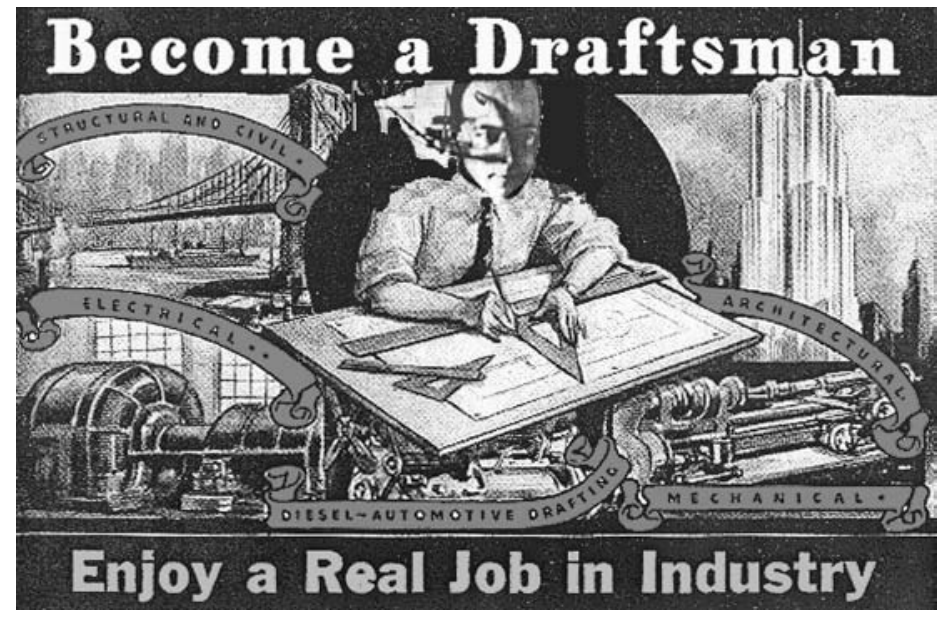

Collage by Marco Frascari, 2010

desire for construction, and then to the users' desire to live well. In these drawings, the architects' soma-sensory brain filters the real ineffable nature of architecture. Because of this consideration I hold the curious belief that architects are natural neurologists. By distilling in construction drawings the powerful axioms "we build buildings and buildings build us," as neurologists in nuce, architects carry on investigations and assessments of architectural thinking and make the builders and the users think within architecture.

There are two ways to verify this neurological quality of the architectural opus: from the top down, using neurological experiments (which I am not qualified to do), and from the bottom up, i.e. from occurrences in the tradition of drawing (which I am competent to do). It has been demonstrated that there is an area of the brain that recognises architecture. In brain imaging, the blood flow increases in a specific area when the person is shown a picture of a building. People who have had a stroke affecting this area often become disoriented because they have lost the ability to recognise buildings as landmarks, even if they can recognise other objects and they navigate their environment by looking to other spatial references (Sternberg 2009: 30). In architecture, this cognitive assimilation of buildings is a productive inference generated by neurons, just as the oral tasting of early childhood is a part of cognitive appropriation. This assimilation becomes an enlightening experience when it takes place sinaesthetically, since it becomes an appropriation of reality obtained through a crossing of human senses. This enlightened assimilation becomes a powerful act of imagination and confers a special virtue upon its practitioners, because through this process of incorporation they can relate the immediate with the mediated in their constructions and constructs.

Physical and emotional interactions are shaped and conditioned by the body and building constraints. This common relational character is underpinned in the brain, by shared neural mechanisms. These neural mechanisms enable the shareable character of actions, emotions and sensations, the earliest constituents of our life. We-ness and intersubjectivity ontologically ground the human condition, in which reciprocity foundationally defines human existence. Emotions recruit a unique modality - internal representation of bodily state - and are tightly connected to motivation. Neuroscientific research may provide information on the ways in which we empathise with building and edifices by emphasising the role of embodied simulation. 
Thinking within architecture activates this system of cells, called mirror neurons, in the frontal lobes, and it is different from thinking about architecture, which activates other kinds of neurons. The implications of the discovery of mirroring neurons, the consequent mirror mechanisms and embodied simulation for empathetic responses to images in general, and to architectural drawings in particular, have not yet been assessed. Nevertheless, architects should challenge the primacy of formal cognition in responses to their drawings and take into account the embodiment of construction in the lines of construction drawings. A crucial element of the constructive response consists of the activation of embodied mechanisms encompassing the simulation of actions, emotions and corporeal sensation. This basic reaction to drawing is essential to understanding the effectiveness both of everyday detailing and of works of superb craftsmanship. Historical, cultural and other contextual factors do not preclude the importance of considering the neural processes that arise in the empathetic understanding of construction documents.

During the penultimate decade of the twentieth century, Giacomo Rizzolatti, Vittorio Gallese and other scientists at the University of Parma discovered what have been called mirror neurons. The discovery of mirror neurons in macaques, and of related mirroring mechanisms in the human brain, has brought a new dimension to the understanding of emotional processes. Emotions and actions are infectious; when we see someone laugh, cry, show disgust, or experience pain, in some sense, we share that emotion. When we see a great actor, musician or athlete perform at the peak of his or her abilities, we can vicariously experience some of what he or she is experiencing. With an understanding of mirror neurons it has became clear just how this potent sharing of experiences takes place within the human brain.

A new emphasis on the relevance of emotional processes for architectural perception can change our understanding of the neural basis of architectural cognition. The implications of the discovery of mirroring mechanisms, and embodied simulation, for empathetic responses to architectural drawings, buildings and building details, have not yet been assessed, but the capacity of architects pre-rationally to make sense of the actions, emotions and sensations of others (users and builders) depends on embodied simulation, a functional mechanism through which the actions, emotions or sensations start their internal representations of the body states that are associated with these architectural stimuli, as if they were engaged in a similar action or experiencing a similar emotion or sensation.

The suggested emotional approach refuses the cognition of the primacy of forms in response to architecture. For this emotional way of conceiving and building architecture, the crucial element of response consists of the activation of embodied mechanisms encompassing the simulation of actions, emotions and corporeal sensation, and these mechanisms are neurologically universal. This basic reaction to architecture is essential to understanding the effectiveness both of everyday buildings and edifices. Historical, cultural and other contextual factors do not preclude the importance of considering the neural processes that arise in the empathetic understanding of architecture.

Activation of the same region of the brain during design of first- and third-person experience of actions, emotions and sensations suggests explicit cognitive evaluation of architectural stimuli. There is probably a mechanism that enables 
direct experiential understanding of objects and the inner world of others. The detection of mirror and canonical neurons explains the neural support structure of the recurrent, but until now unexplained, feeling of a combination of physical and psychical reactions to the built environment by the implied movements and emotions involved in its use; mirror neurons also offer the possibility of a clearer understanding of the relationship between responses to the perception of emotions within architecture.

Understanding the intentions of others while watching their actions, and figuring out how to control their movement with the environment, is one of the undertakings fundamental in architectural conceiving. The neural and functional mechanisms underlying this ability are still poorly understood, but successful and useful architecture is evidence of architects using this ability. Vittorio Gallese, a neuroscientist, working with David Freedberg, an art historian, argued that when we look at images we are involved in empathy by having the body reacting with sensations, actions, emotions and motions to works of art (Freedberg and Gallese 2008, and Gallese and Freedberg 2007). For late nineteenthcentury architectural historians such as Heinrich Wöllflin and August Schmarsow, bodies and their sensory responses became the medium and analogue for experiential encounters with buildings. Theodore Lipps, a German philosopher, discussed the role of empathy in aesthetic experience and introduced it in psychology, extending the concept of Einfühlung to the domain of intersubjectivity, which he characterised as empathy with inner imitation of the perceived behaviour of others (Lipps 1965). In Lipps' writings, we find the first suggestion of a relationship between the inner imitation and the capacity of understanding others by ascribing to them feelings, emotions and thoughts.

Mirror-neuron research offers sufficient empirical evidence to suggest that architects' drawings induce an empathetic engagement of builders. The architects' gestures in producing the construction drawings induce the empathetic engagement of the builder, by activating simulation of the motor programme that corresponds to the gesture implied by the trace. The marks of construction drawings are the visible traces of goal-directed movements; hence, they are capable of activating the relevant motor areas in the builder's brain.

Emotionally charged drawings can capture attention, bias perception, modify memory and guide judgments and decisions. Ralph Liebing, a specialist in the construction industry, points out that builders cannot complete deficient construction drawings: "Contractors do not know the thinking, reasoning, and rationale behind the design and documentation of the project" (1999: 21). This does not apply to emotionally rich non-trivial construction drawings because their poignant quality carries the thinking within architecture that is at the foundation of conceiving that specific design (see Eich et al 2000 and Winkielman et al 2007). George M. Grant, Vice-President of Halmar Builders, has drawn attention to a troublesome situation: "The CAD system has been wonderful for architects. But do they know how to build what they're drawing? Constructability is one of the biggest problems I find" (quoted in Bisharat 2004: 8).

Constructability was the question posed by Carlo Lodoli, an eighteenth-century Franciscan priest, mathematician and censor of the Venetian Republic, who was also a subtle architectural theoretician and an influential if peripatetic teacher of Venetian noblemen. By laying down pieces of building elements and rolls of drawings in the garden of the Commissariato di Terra Santa in Venice, Lodoli ad- 
vocated a correct use of representation in the practice of architecture. He called these drawings technographies (tecnografie).

Technographies of not-yet-built artefacts are powerful examples of non-trivial construction drawings because they reveal the common substratum between consciousness and matter. Technographies present in themselves the same qualities that are negated in current construction drawings. They do not search for a likeness as the basis for relating building and an architectural conception, but for a mutual measure derived from a familiar nature, which constructs both the drawing and the edifice: the emotions.

Technographies are demonstrations related to the built world through emotional representations that contrast conventional notations of geometrical and factual construction, since they deal with the description of processes of construction. Technographies embody the Janus-like nature of technology, since they are a perfect instance of the non-separation of the emotions ruled by the techne of logos from the events of the logos of techne. Technographies are mirrors of constructions demonstrated in representation. They help architects to perform one of the most difficult tasks of their profession: they give the appropriate measure of building as matrix of the edifying nature of an edifice. Architectural technographies belong to the realm of masterpieces because they are inaugurations of construction, not merely likenesses of future buildings. They are anagogic demonstrations of construction.

Although it is not known if Gianbattista Piranesi actually frequented the open seminars of Lodoli's peripatetic school, during his early training in Venice, his associations with Lodoli and Memmo have been documented. Memmo referred to the Della magnificenza ed architettura de' Romani (1761) as an example of Lodolian thinking (Memmo 1833-34, vol. 2: 139). Piranesi produced these series of "views" and archaeological representations of various buildings, ruins and areas of Rome. He created these prints hoping to inspire others to use ancient Roman ideas and forms to create a new architecture. He also used this emotionally-loaded opus to promote his belief that Roman architecture owed its roots to the Etruscans rather than the Greeks. In many of Piranesi's prints, fragments of architectural artefacts are represented holding down overlapping rolls of drawings showing plan, section, elevations and details and, a few times, a perspective view: possibly, a graphic memento of how architecture was presented and discussed in Lodoli's garden. These emotional prints can be considered the basic model of non-trivial construction drawings. They allow the grasping of construction by grasping the idea and the object.

Grasping requires a coding of the object's intrinsic properties (size and shape), and the transformation of these properties into a pattern of construction movements through embodied simulation, implied gesture. Feeling the movement behind the marks constitutes constructive empathetic responses that are the fundamental response to construction drawings. Underlying such responses is the process of embodied simulation that enables the direct experiential understanding of the intentional and emotional contents of drawings. This basic emotional reaction to drawings becomes essential to any understanding of their effectiveness as generator of architecture, because emotion processing is grounded in modality-specific systems, in which conceptual operations involve the partial reactivation or even recreation (simulation) of the actual emotion experience. Emo- 
tion concepts recruit a unique modality - internal representation of bodily state - and are tightly connected to motivation. Then construction drawings revert to a dialogical apparatus that has the capability to guide, determine, interpret and mould responses, opinions or discourses of the trades involved in the erecting of building.

\section{References}

Alberti, L. (1991). On Painting (C. Grayson, Trans.). Harmondsworth: Penguin.

Agamben, G. (2009). What Is an Apparatus? and Other Essays (D. Kishik and S. Pedatella, Trans.). Stanford: Stanford University Press.

Bisharat, K. A. (2004). Construction graphics: A practical guide to interpreting working drawings. Hoboken, New Jersey: John Wiley \& Sons.

Eich, E., Kihlstrom, J. F., Bower, G. H., Forgas, J., and Niedenthal, P. (2000). Cognition and Emotion. New York: Oxford University Press.

Frascari, M. (1981). Sortes Architecti. PhD Dissertation, University of Pennsylvania.

Freedberg, D. and Gallese, V. (2008). Movimento Emozione Empatia. Prometeo, 26: 103, 52-59.

Gallese, V. and Freedberg, D. (2007). Mirror and canonical neurons are crucial elements in esthetic response, Trends in Cognitive Sciences, 11: 10, 411.

Grant, G.M. (1998). Listening to Contractors. Architectural Record, February.

Liebing, R. (1999). Architectural Working Drawings. Hoboken, New Jersey: John Wiley \& Sons, 4th edition.

Lipps, T. (1965). Empathy and Aesthetic Pleasure. In K. Aschenbrenner and A. Isenberg, Aesthetic Theories: Studies in the Philosophy of Art. Prentice Hall, New Jersey, 1965, 404-412.

Major, T. (1768). The Ruins of Paestum, otherwise Posidonia, in Magna Graecia. London: James Dixwell.

Memmo, A. (1833-34). Elementi dell'architettura Lodoliana o sia l'arte del fabbricare con solidità scientifica e con eleganza non capricciosa, Edizione corretta e accresciuta dall'autore, vol. 2. Zara: Fratelli Battara.

Ortenberg, A. (2005). Drawing practices: The art and craft of architectural representation. Ph.D. Dissertation, University of California, Los Angeles.

Schmarsow, A. (1994). Essence of Architectural Creation, (1893) in H. F. Mallgrave and E. Ikonomou (eds), Empathy, form and Space (281-297). Getty Center Publications: Santa Monica.

Sternberg, E.M. (2009). Healing Spaces. Cambridge: Harvard University Press.

Winkielman, P., Knutson, B., Paulus, M. P. and Tujillo, J. T. (2007). Affective influence on decisions: Moving towards the core mechanisms. Review of General Psychology, 11: 179-192.

Wölfflin, H. (1994). Prolegomena to a Psychology of Architecture (1886) in H. F. Mallgrave and E. Ikonomou (eds), Empathy, Form and Space (149-162). Getty Center Publications: Santa Monica. 